\title{
Isothermal Calorimetric Observations of the Effect of Welding on Compatibility of Stainless Steels with High-Test Hydrogen Peroxide Propellant
}

\author{
Rudy Gostowski, PhD. \\ Marshall Space Flight Center, National Aeronautical and Space Administration, TD40, \\ Huntsville, AL
}

\section{Introduction}

High-Test Hydrogen Peroxide (HTP) is receiving renewed interest as a monopropellant and as the oxidizer for bipropellant systems. HTP is hydrogen peroxide having concentrations ranging from 70 to $98 \%$. In these applications the energy and oxygen released during decomposition of HTP is used for propulsion.

$$
2 \mathrm{H}_{2} \mathrm{O}_{2}(l) \rightarrow 2 \mathrm{H}_{2} \mathrm{O}(g)+\mathrm{O}_{2}(g) \quad \Delta H_{r}=2887.0 \mathrm{~J} \mathrm{~g}^{-1} \text { anhydrous HTP [1] }
$$

However, incompatibility with structural materials will lead to decomposition of HTP in areas of the propulsion system that does not result in useful energy production. In addition, incompatibility may cause undesirable pressure and temperature rises and loss of capacity. Compatibility is generally thought to be controlled by complex interactions of the surface area, the chemical constituency and the surface finish of the material. Therefore, implementation of HTP as a propellant requires testing to determine the compatibility of structural materials for fabrication of the propulsion system. Compatibility has been expressed functionally with a series of classes ranging from one to four with one being preferred [2]. Percent Active Oxygen Loss per Week (\%AOL/wk) has been used to quantitatively express compatibility.

D:Locuments and Settings/gostorclMy Documents Papers \& PresentationslWelding Effects on HTP DecompositionLffect of Welding on Compatibility of Stainless Steel with High-Revision 2.rtf 
$\% A O L / w k=100\left(\mathrm{~W}_{1} \mathrm{C}_{1}-\mathrm{W}_{2} \mathrm{C}_{2}\right) / \mathrm{W}_{1} \mathrm{C}_{1}$

$W_{1}$ and $W_{2}$ represent the initial and final masses of HTP solution respectively. $C_{1}$ and $C_{2}$ are the initial and final HTP mass fractions. To relate these quantitative measurements to the functional compatibility designations, metal samples having a \%AOL/wk of $\leq 5$ are assigned [3] to Class 1 , while those having a value between 5 and 80 are considered Class 2. Class 3 materials have a $\%$ AOL $/ w k>80$.

Isothermal heat-conduction microcalorimetry (IMC) permits measurement of the energy released when HTP decomposes which indirectly provides \%AOL/wk data for the sample and facilitates class ranking.

In propulsion systems components must be fabricated and connected using available joining processes. Welding is a common joining method for metallic components. The goal of this study was to compare the HTP compatibility of welded vs. unwelded stainless steel.

\section{Experimental}

Propulsion grade high-test hydrogen peroxide ( $90 \%$, FMC, Inc), reagent hydrogen peroxide (35\%, Spectrum), nitric acid (70\%, trace metal grade, Fisher Scientific) and sodium hydroxide solution $(50 \%$, Fisher Scientific) were used as received. Stainless steel sheet $(0.15 \mathrm{~cm}$ thickness, CRES 316L and CRES 304L, Penn Stainless Products, Inc.) was cut into panels (10.2 $x 10.2 \mathrm{~cm}$ ). One panel of each alloy was Tungsten Inert Gas (TIG) welded with purge gas (Helium), one welded without purge gas and one was not welded. The panels were milled into coupons $(3.8 \times 1.0 \mathrm{~cm})$. The dimensions of the coupons including the weld bead were

D:LDocuments and Settings/gostorclMy Documents|Papers \& Presentations $\mid W e l d i n g$ Effects on HTP DecompositionLEffect of Welding on Compatibility of Stainless Steel with High-Revision 2.rtf 
determined using calipers and the surface area estimated (Table 1). The samples were then evaluated with a Surface Roughness Tester (Surftest 402 Series 178, Mitutoyo) yielding the root mean square of the deviations of the surface profile from the mean line $(\mathrm{Rq})$ and the maximum peak to valley height $(R \max )$. Results are also listed in Table 1. The coupons were cleaned in acetone and detergent and rinsed with deionized water. Coupons were passivated by soaking in $70 \%$ nitric acid for five hours, rinsed, soaked in $35 \%$ hydrogen peroxide for four hours, rinsed in deionized water and air-dried. Molded borosilicate serum bottles $(30 \mathrm{ml}$, Wheaton Science Products) were passivated by soaking in sodium hydroxide (10\%) for one hour, rinsed, soaked in nitric acid (35\%) for one hour, soaked in 35\% hydrogen peroxide for twenty four hours, rinsed in deionized water and air dried.

An Isothermal Microcalorimeter (Model 4400, Water Bath Model 7238, Calorimetry Sciences Corp, Provo, UT) was used to obtain heat flow measurements at $60^{\circ} \mathrm{C}$. The unit was permitted to thermally equilibrate at the set temperature for 24 hours and then calibrated against an internal resistance heater standard. Three measurement cells were evaluated against a reference cell holding a sealed vial containing deionized water $(20 \mathrm{~mL})$. Aluminum closures were used with trifluoroethylene (TFE)-faced silicone liners for the reference and sample vials. Background heat flows $\left(P_{\mathrm{B}}, \mu \mathrm{W} \mathrm{g}^{-1}\right.$ anhydrous HTP) were measured for three vials containing only hydrogen peroxide $(90 \%, 20 \mathrm{~mL})$. The anhydrous HTP mass was taken as $90 \%$ of the total fluid mass. Heat flows were constant over the 50-hour observation interval.

Vials were opened, metal sample coupons added and recapped. In all cases the heat flow quickly attained a thermal equilibrium state ( $<15$ hours) followed by a slow rise to a peak value $\left(P_{\mathrm{S}+\mathrm{B}}, \mu \mathrm{W} \mathrm{g}^{-1}\right.$ anhydrous HTP) within 70 to 320 hours and subsequently diminished. The D:Locuments and Settings/gostorclMy Documents Papers \& PresentationslWelding Effects on HTP DecompositionlEffect of Welding on Compatibility of Stainless Steel with High-Revision 2.rtf 
background value $\left(P_{\mathrm{B}}\right)$ representing a sum of the homogeneous HTP decomposition and the heterogeneous HTP decomposition on the surface of the vial was subtracted from the peak heat flow $\left(P_{\mathrm{S}+\mathrm{B}}\right)$. The resulting value $\left(P_{\mathrm{S}}, \mu \mathrm{W} \mathrm{g}^{-1}\right.$ anhydrous HTP) corresponded to the maximum heterogeneous HTP decomposition on the surface of the coupon.

As shown in Equation 2, $P_{\mathrm{S}}$ was converted to a first order rate constant $\left(k, \mathrm{~s}^{-1}\right)$ by division with the heat of reaction for the decomposition of hydrogen peroxide $\left(\Delta H_{r}=2887.0 \mathrm{x}\right.$ $10^{6} \mu \mathrm{W} \mathrm{s} \mathrm{g}^{-1}$ ) [1]. Using Equation 3 the resulting first order rate constant was converted from reciprocal seconds to $\% \mathrm{AOL} / \mathrm{wk}$ with the results listed in Table 1.

$$
\begin{aligned}
& k=\frac{P_{S}}{\Delta H_{r}} \\
& \% A O L / w k=\left(6.048 \times 10^{7}\right) k
\end{aligned}
$$

\section{Results}

Table 1

Surface area, finish of samples and percent active oxygen loss per week ${ }^{2, b}$

\begin{tabular}{llllll}
\hline Material & Joining Method & Area $\left(\mathrm{cm}^{2}\right)$ & Surface Roughness & Maximum \\
& & & & $\% A O L / w k$ \\
& & & & & \\
\hline & & & & & \\
\hline CRES 316L & No weld & $10.31 \pm 0.02$ & $0.97 \pm 0.25$ & $0.30 \pm 0.09$ & $5.9 \pm 0.5$ \\
\hline CRES 304L & No weld & $10.30 \pm 0.04$ & $1.14 \pm 0.18$ & $0.33 \pm 0.15$ & $27.9 \pm 1.6$ \\
\hline CRES 316L & TIG, He purge & $9.36 \pm 0.14$ & $3.66 \pm 1.02$ & $1.07 \pm 0.19$ & $34.0 \pm 10.0$ \\
\hline CRES 304L & TIG, He purge & $9.43 \pm 0.04$ & $2.29 \pm 1.02$ & $1.83 \pm 1.11$ & $68.2 \pm 11.5$ \\
\hline CRES 316L & TIG, No purge & $9.40 \pm 0.11$ & $32.26 \pm 14.02$ & $15.42 \pm 2.39$ & $36.1 \pm 4.1$ \\
\hline
\end{tabular}

D:LDocuments and Settings/gostorclMy Documents Papers \& PresentationslWelding Effects on HTP DecompositionLEffect of Welding on Compatibility of Stainless Steel with High-Revision 2.rtf

Page 4 of 7

9/3/03 


\begin{tabular}{llllll}
\hline CRES 304L & TIG, No purge & $9.46 \pm 0.11$ & $106.93 \pm 61.21$ & $17.81 \pm 2.32$ & $94.5 \pm 3.1$
\end{tabular}

${ }^{2}$ Average of three coupons.

${ }^{b} 90 \%$ confidence level.

${ }^{\mathrm{c}}$ Maximum peak to valley height.

${ }^{d}$ Root mean square of the deviations of the surface profile from the mean line.

Unwelded CRES 316L shows good compatibility and by the rating system is nearly Class 1 .

CRES 304L is a Class 2 material. Welded CRES 316L and welded CRES 304L have significantly less compatibility than their unwelded counterparts with the CRES 304L falling beyond the upward limit of Class 2 materials. When welded without purge gas the CRES 316L is not significantly different from the metal welded with the gas. However, CRES 304L welded without purge gas has a much higher \%AOL/wk and would be considered a Class 3 material.

\section{Discussion}

As mentioned previously, compatibility is determined by the surface area, the chemical constituency and the surface finish of a material. In this investigation exposed area is obviously not at factor as the welded samples had a slightly smaller surface than the unwelded, but were more reactive. The chemical makeup of welded CRES 316L and welded CRES 304L have been observed in the literature to change from the parent material as chromium and iron are segregated in zones [4-6]. In particular, the ratio of chromium to iron [6] in CRES 316L increased from 0.26 to 0.79 in the heat affected zone (HAZ) of the weld and to 1.52 in the weld

bead itself. In CRES 304L the ratio of chromium to iron increased from 0.28 to 0.44 in the HAZ and to 0.33 in the weld bead. It is possible that the increased reactivity of the welded samples and of those welded without purge gas is due to this segregation phenomenon. Likewise the D:LDocuments and Settings/gostorclMy Documents Papers \& Presentations/Welding Effects on HTP DecompositionlEffect of Welding on Compatibility of Stainless Steel with High-Revision 2.rtf 
reactivity increased in keeping with the greater roughness of the welded and welded without purge gas samples. Therefore enhanced roughness may also be responsible for the increased reactivity.

\section{Conclusions}

In summary, HTP reactivity increased due to welding concurrently with formation of segregation zones and increased roughness. These effects were even greater when purge gas was not used. Causality between these factors while reasonable was not established and their fractional contributions to reactivity were not determined.

\section{Acknowledgments}

The author is grateful to Bill Stanton (Marshall Space Flight Center, Metallic Materials Group) for welding the various specimens and to Yvonne Villegas (NASA-Undergraduate Student Research Program), Genne Nwosisi (NASA-Minority Programs) and Jennifer Baldridge (NASAUndergraduate Student Research Program) for their help in preparation and execution of the IMC analysis.

\section{References}

[1] W.C. Schumb, C.N. Satterfield and R.L. Wentworth, Hydrogen Peroxide, Reinhold, Baltimore, 1955, p. 249.

[2] W.C. Schumb, C.N. Satterfield and R.L. Wentworth, Hydrogen Peroxide, Reinhold, Baltimore, 1955, p. 163.

D:IDocuments and Settings/gostorclMy Documents $\backslash$ Papers \& Presentations $\backslash$ Welding Effects on HTP DecompositionlEffect of Welding on Compatibility of Stainless Steel with High-Revision 2.rtf 
[3] Bulletin \#104: Materials of Construction for Equipment in Use with Hydrogen Peroxide, FMC, 1966, p. 48.

[4] T. Takalo, N. Suutala and T. Moisio, Metall. Trans A. 10A (1979) 1173.

[5] J. Foulds and J. Moteff, Metall. Trans. A. 13A (1982) 173.

[6] M. Ahmad, K.A. Shoaib, M.A. Shaikh and J.I. Akhtar, J. Mat. Sci. 29 (1994) 1169.

D:Locuments and Settings/gostorclMy Documents Papers \& PresentationslWelding Effects on HTP DecompositionlEffect of Welding on Compatibility of Stainless Steel with High-Revision 2.rtf

Page 7 of 7

9/3/03 


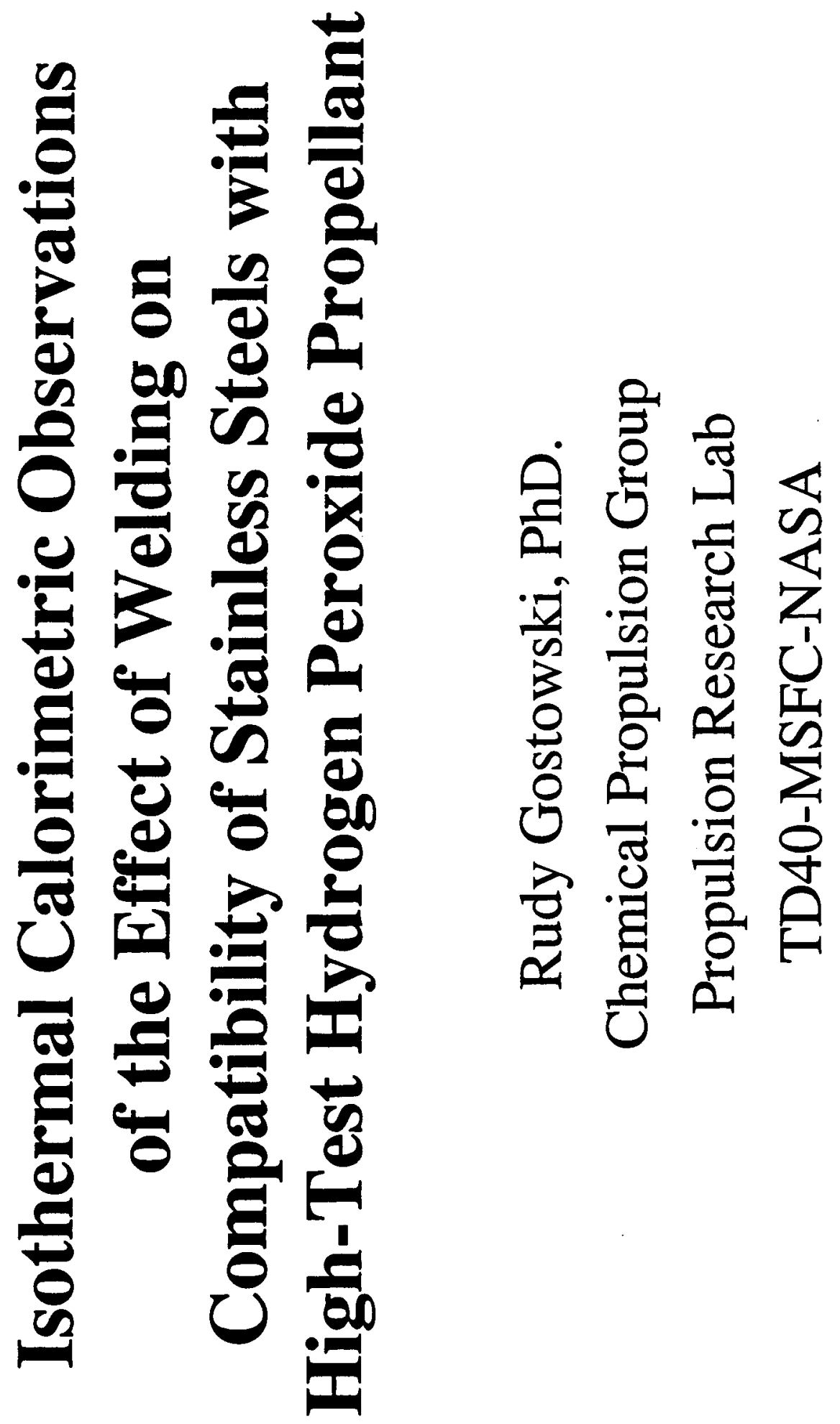




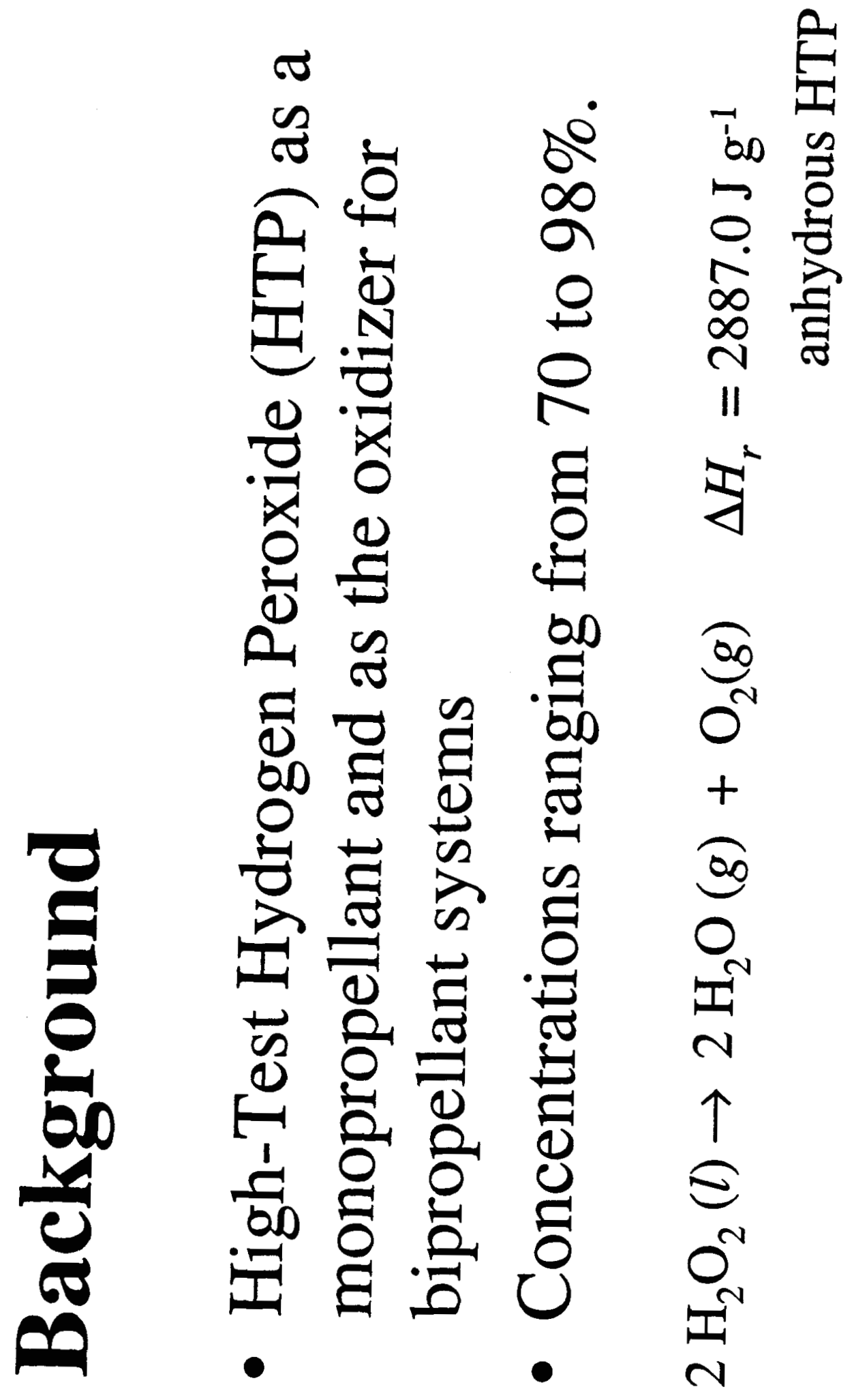




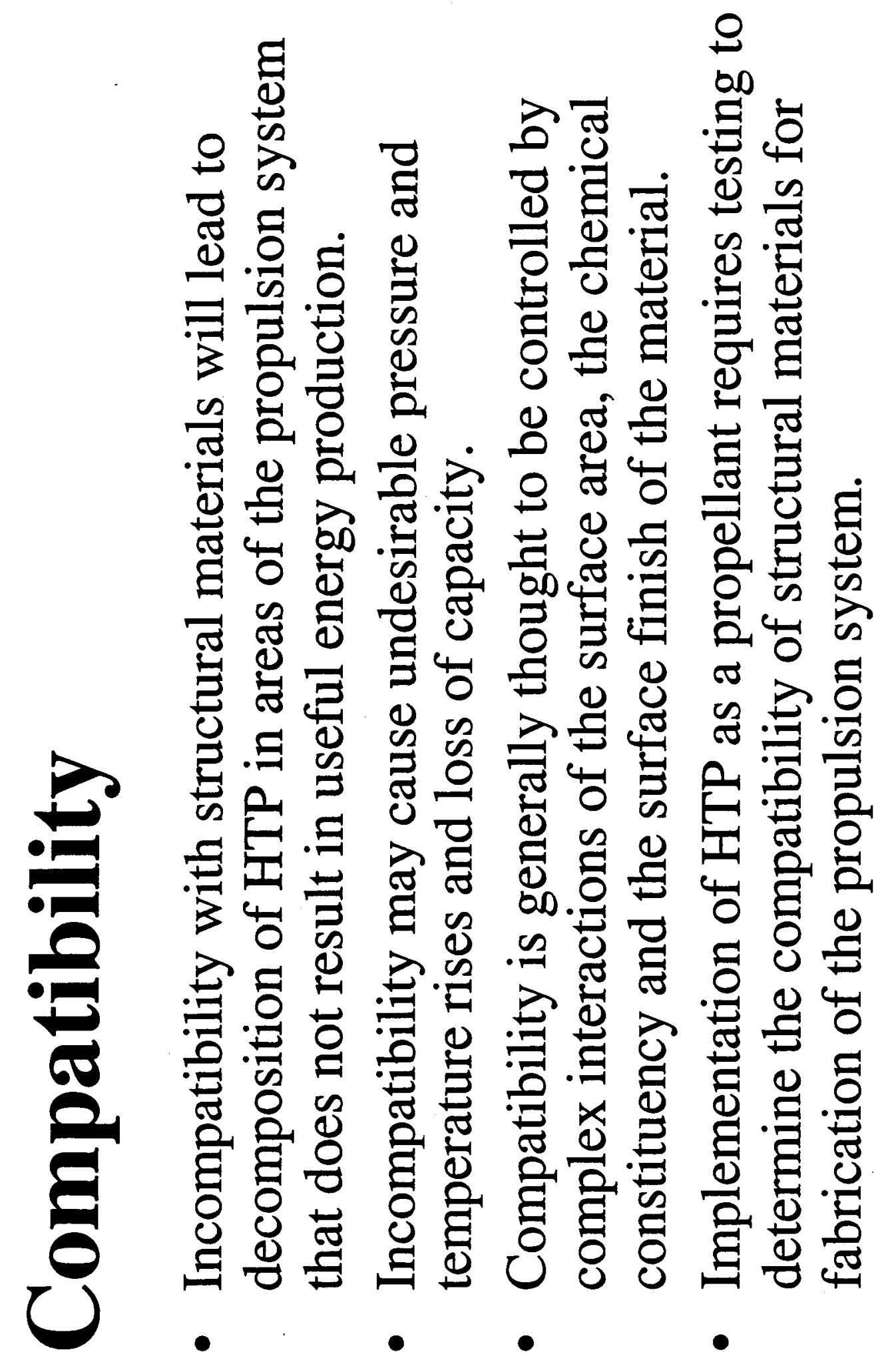




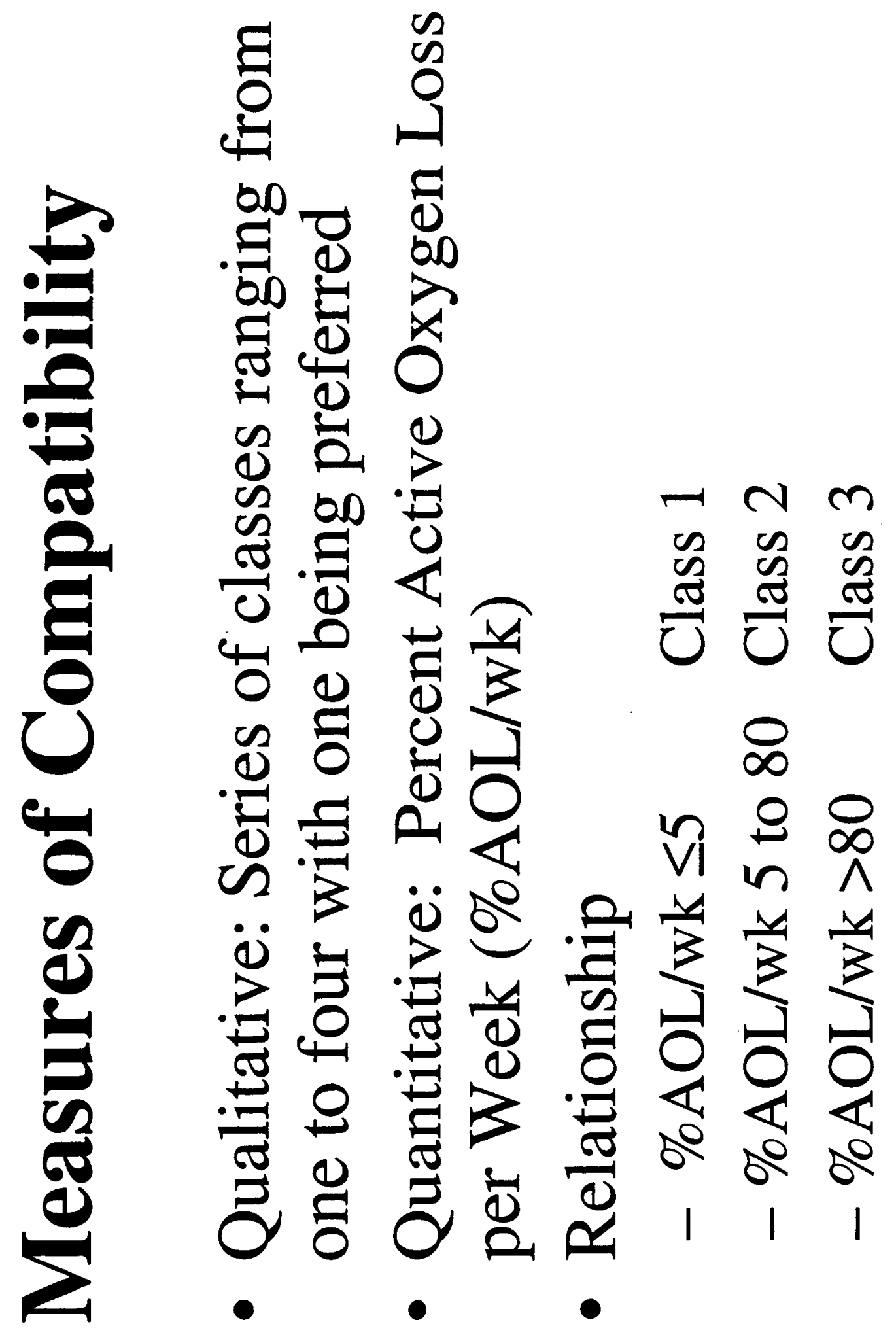



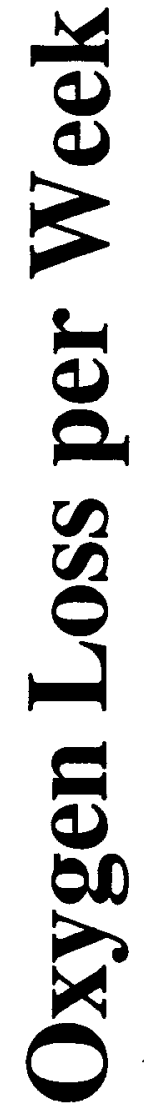

(1)

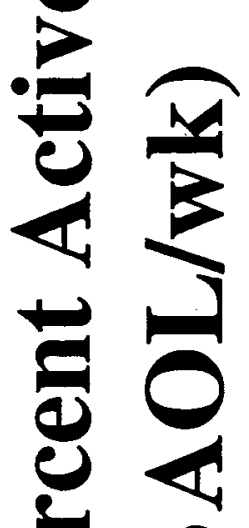

a
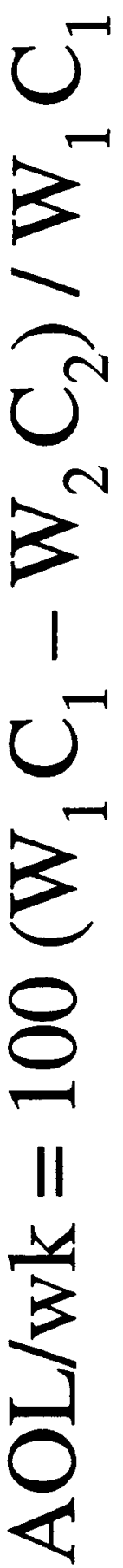

so

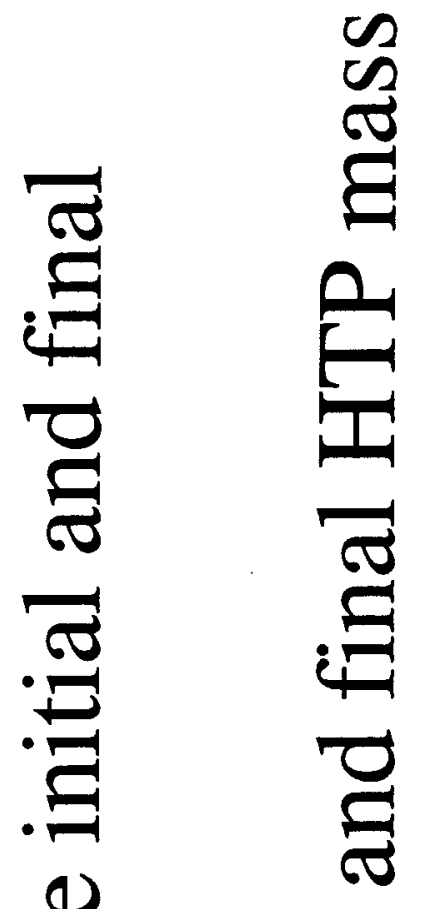

0
$+\infty$

(4)

표

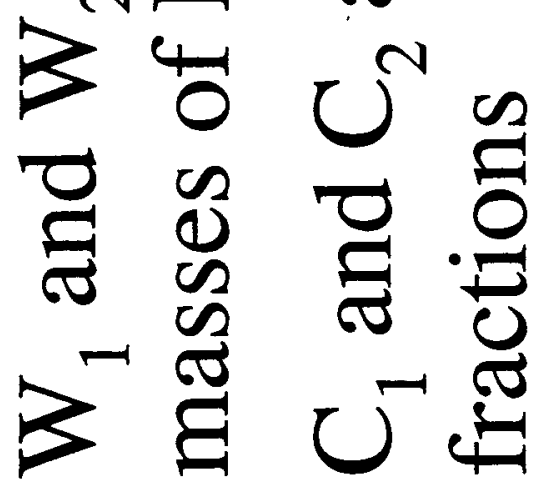

- 


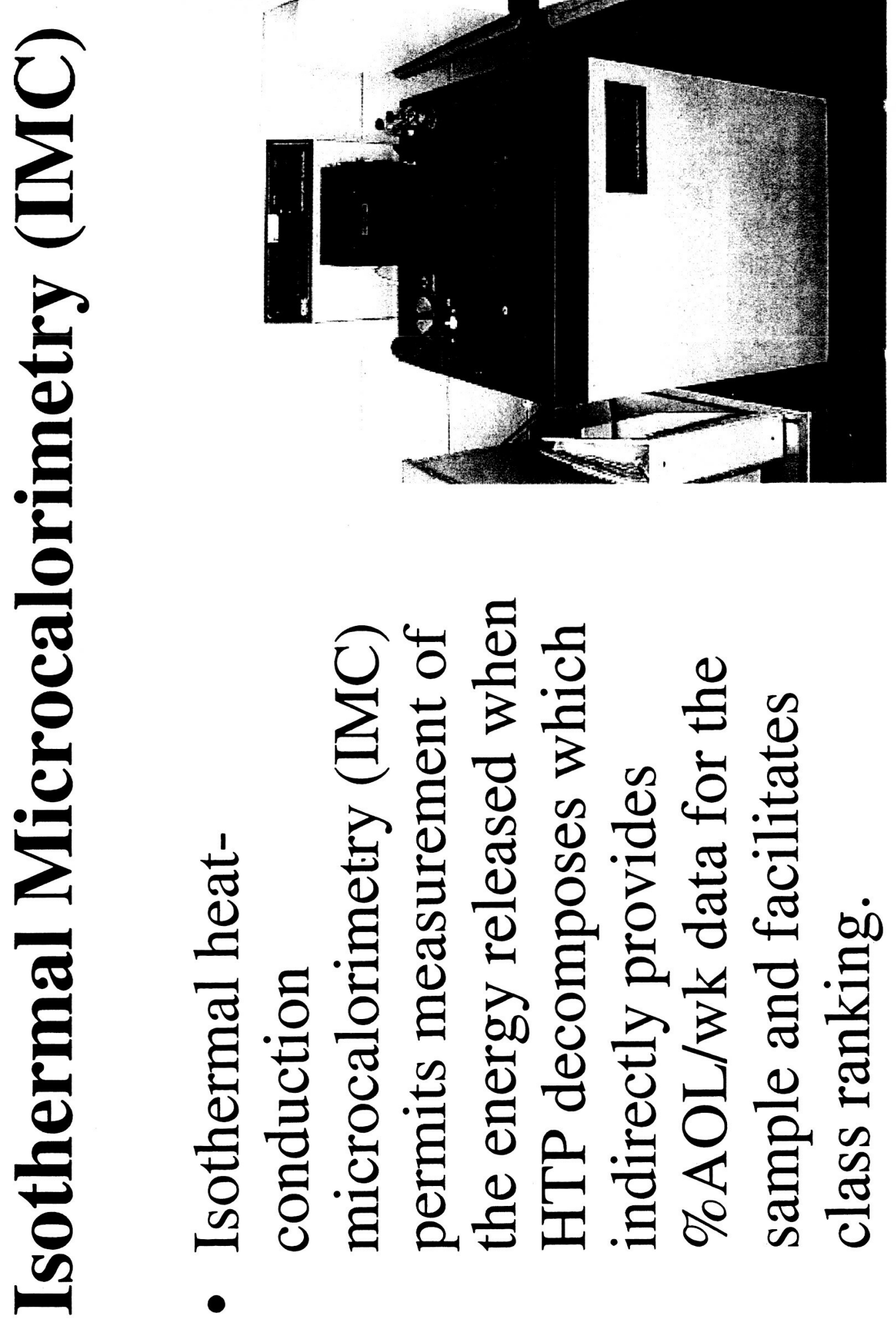




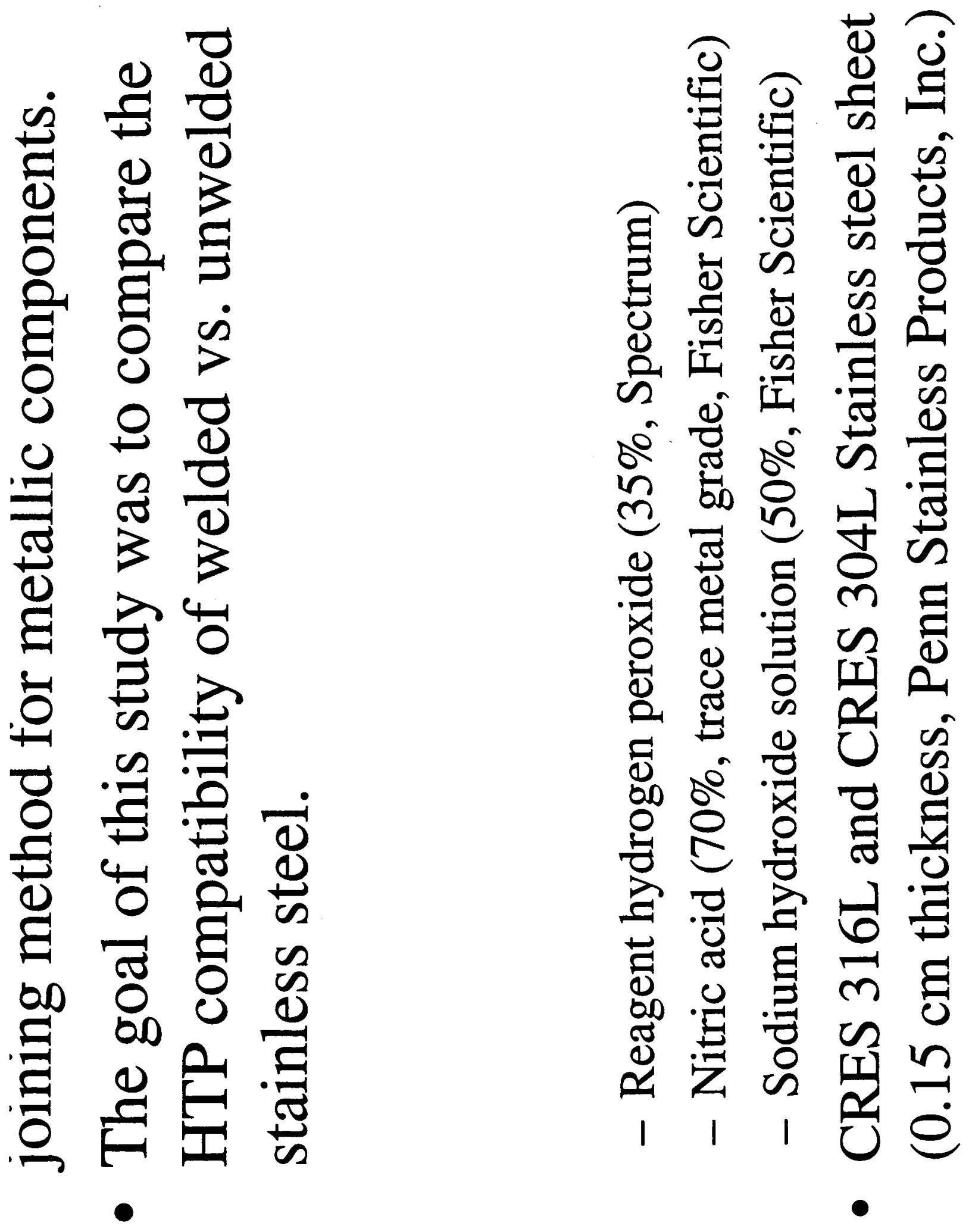




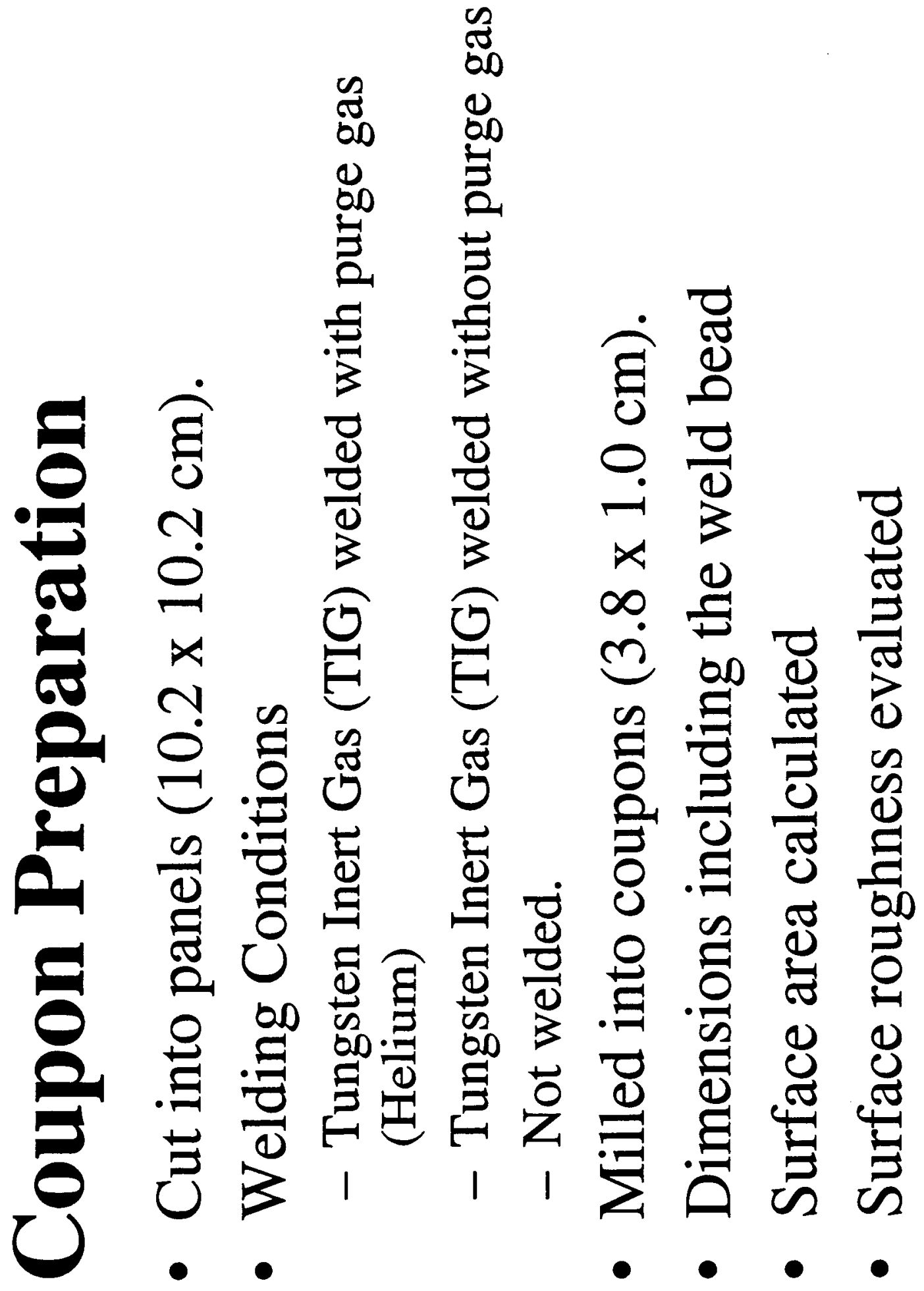




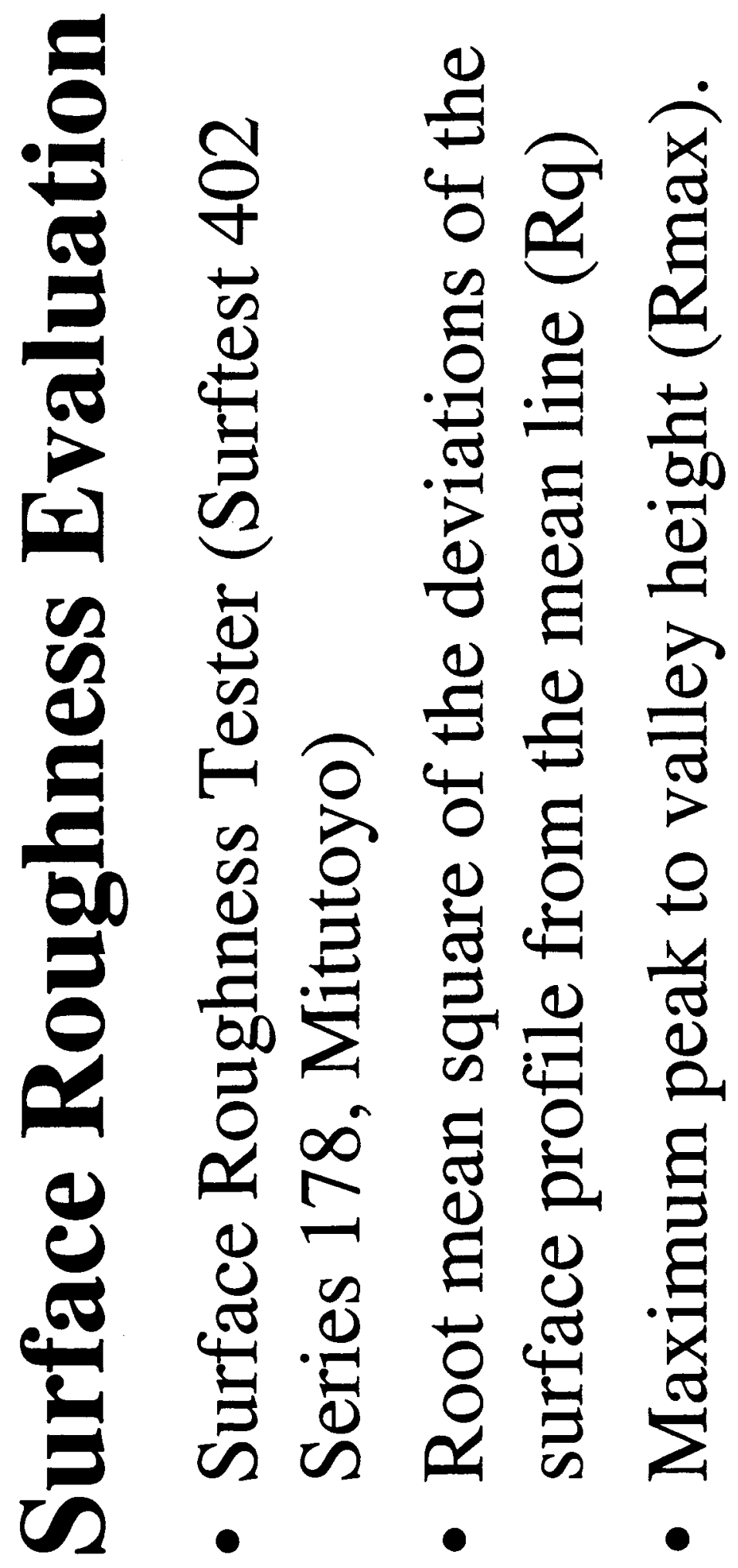




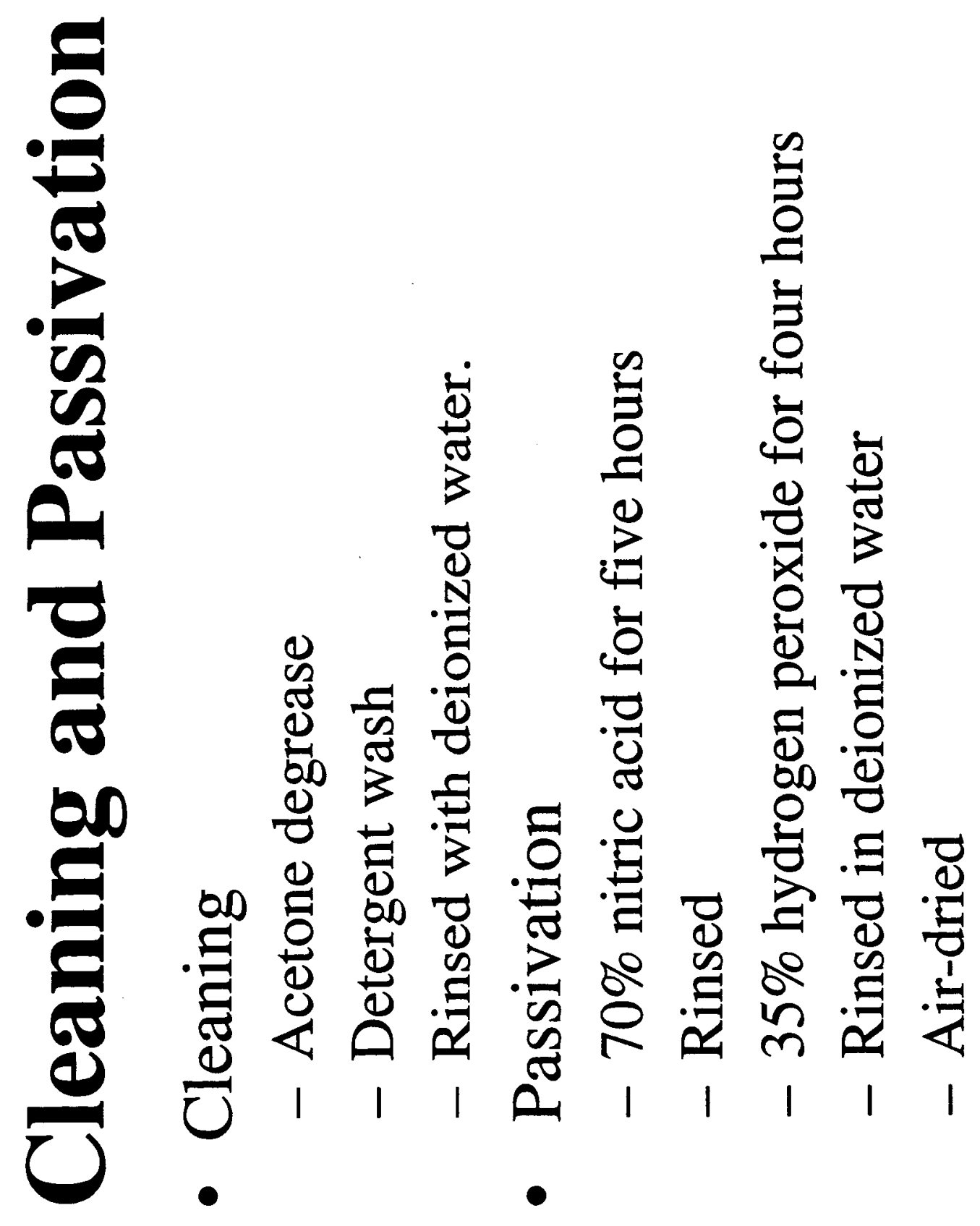




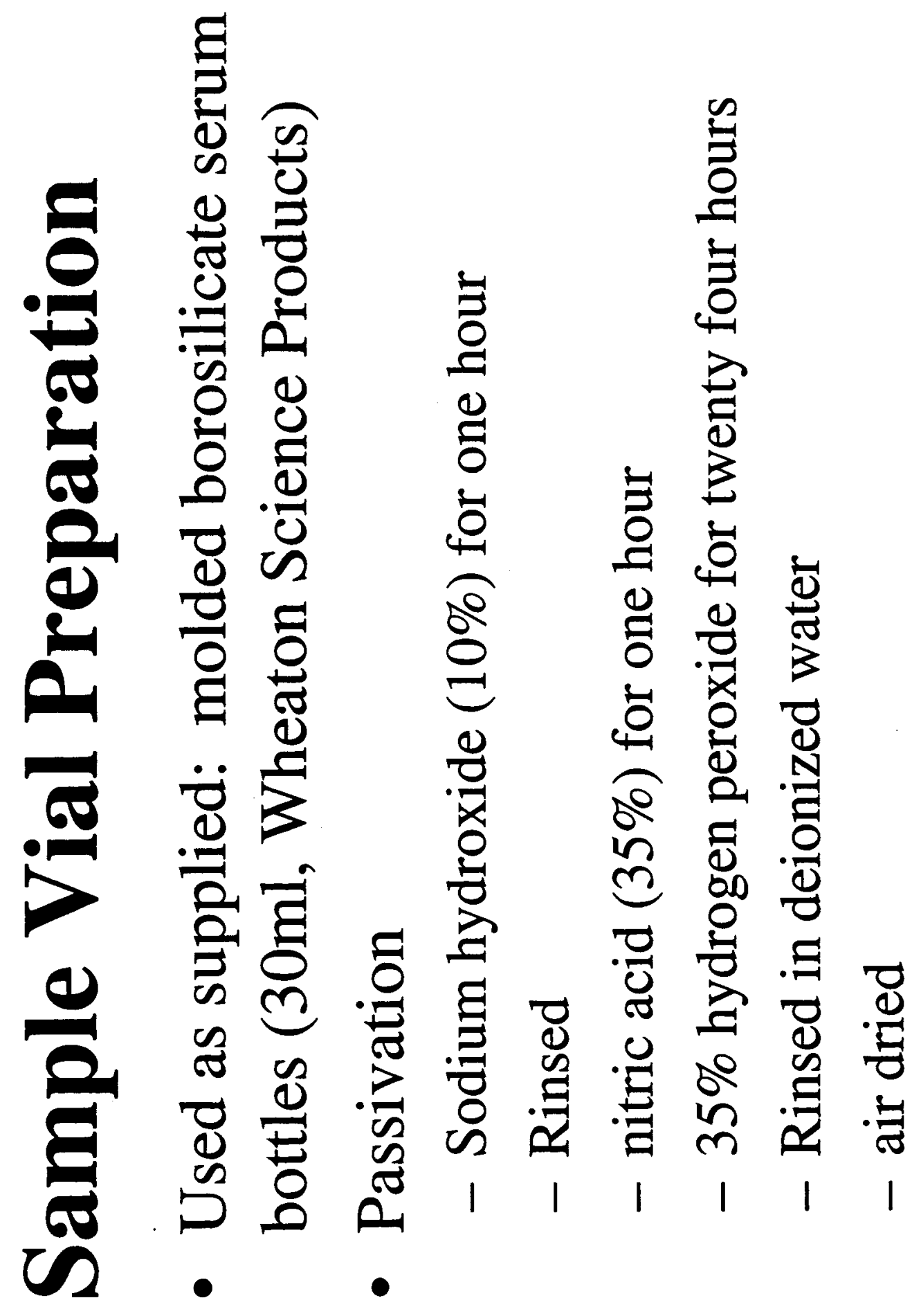




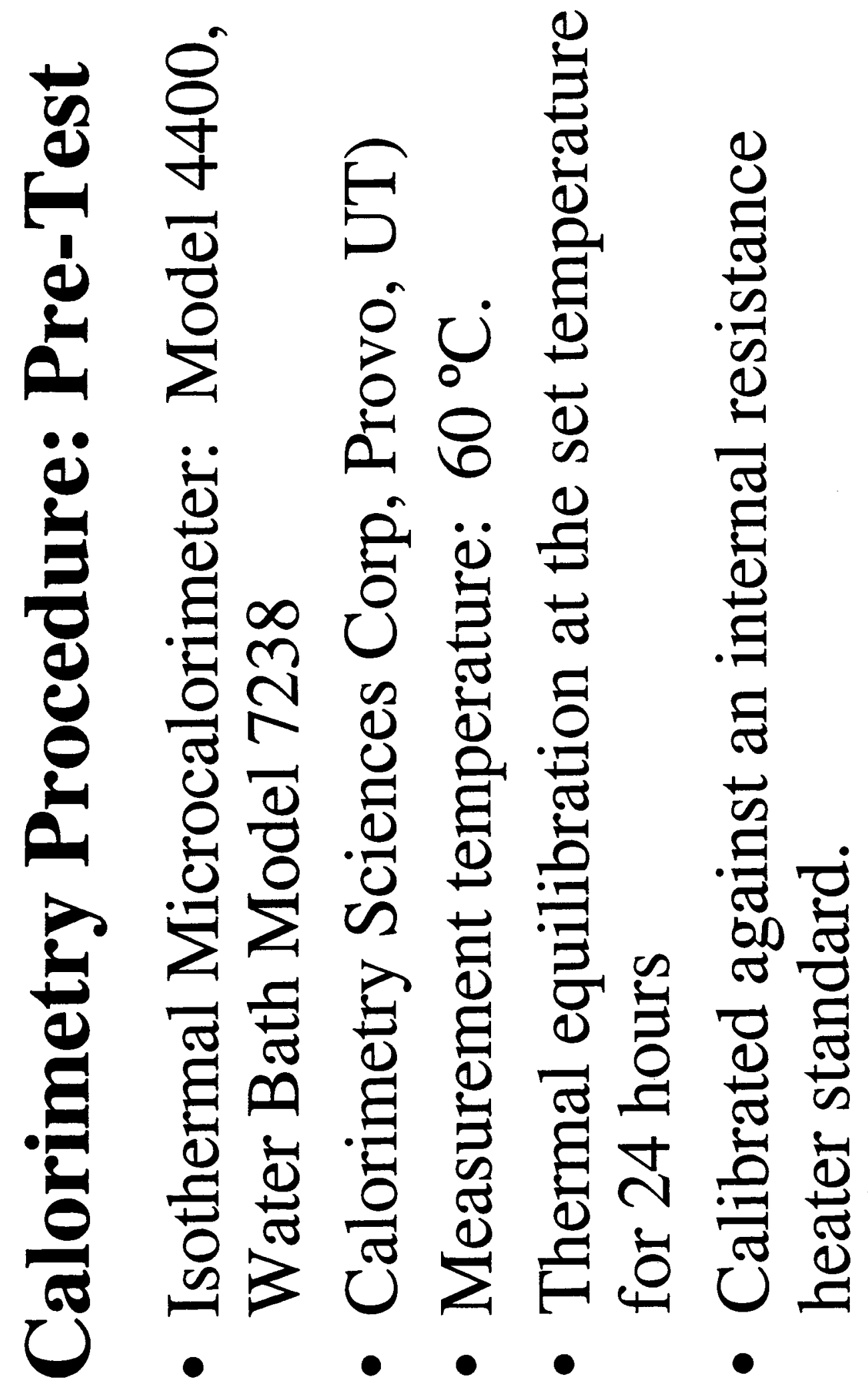




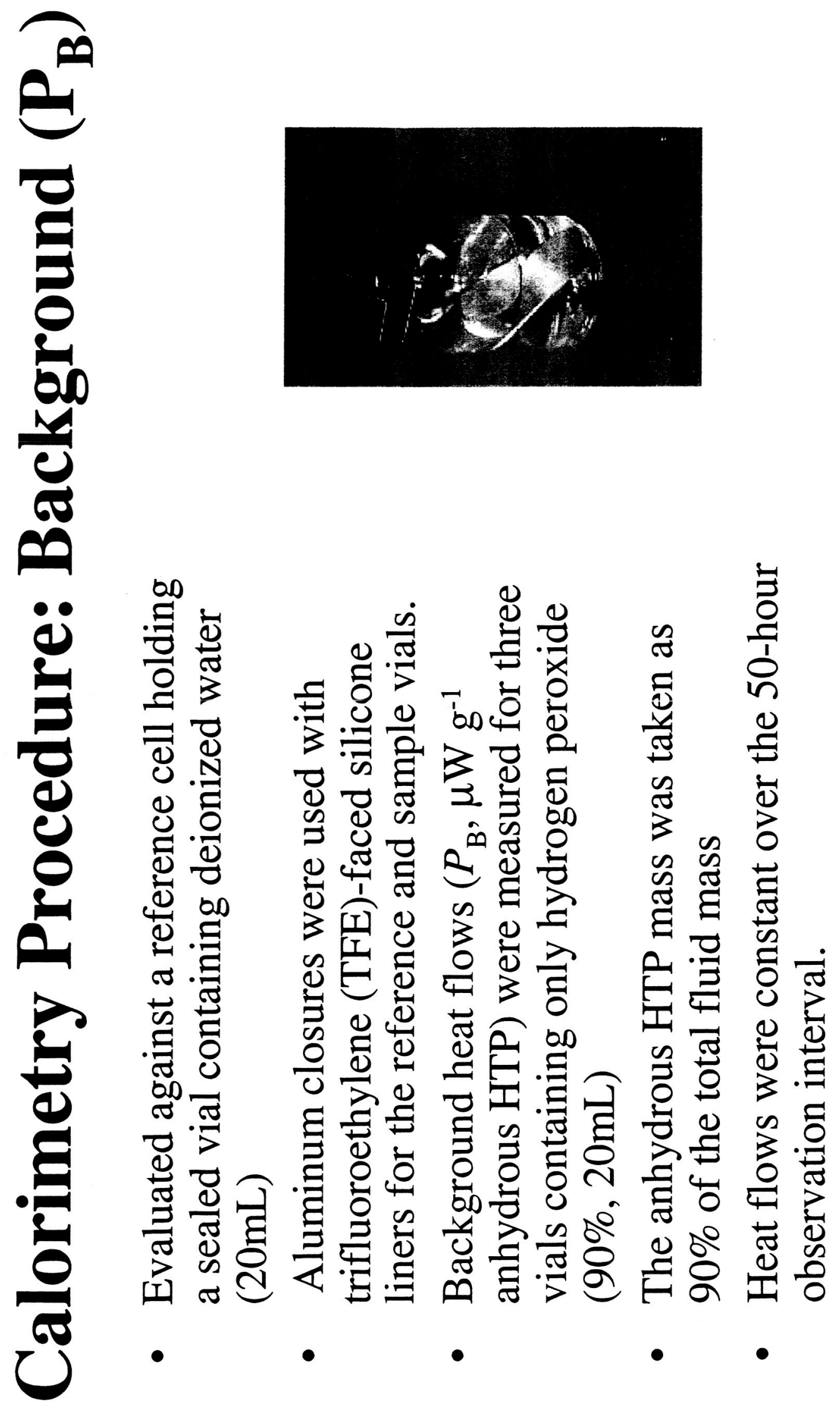




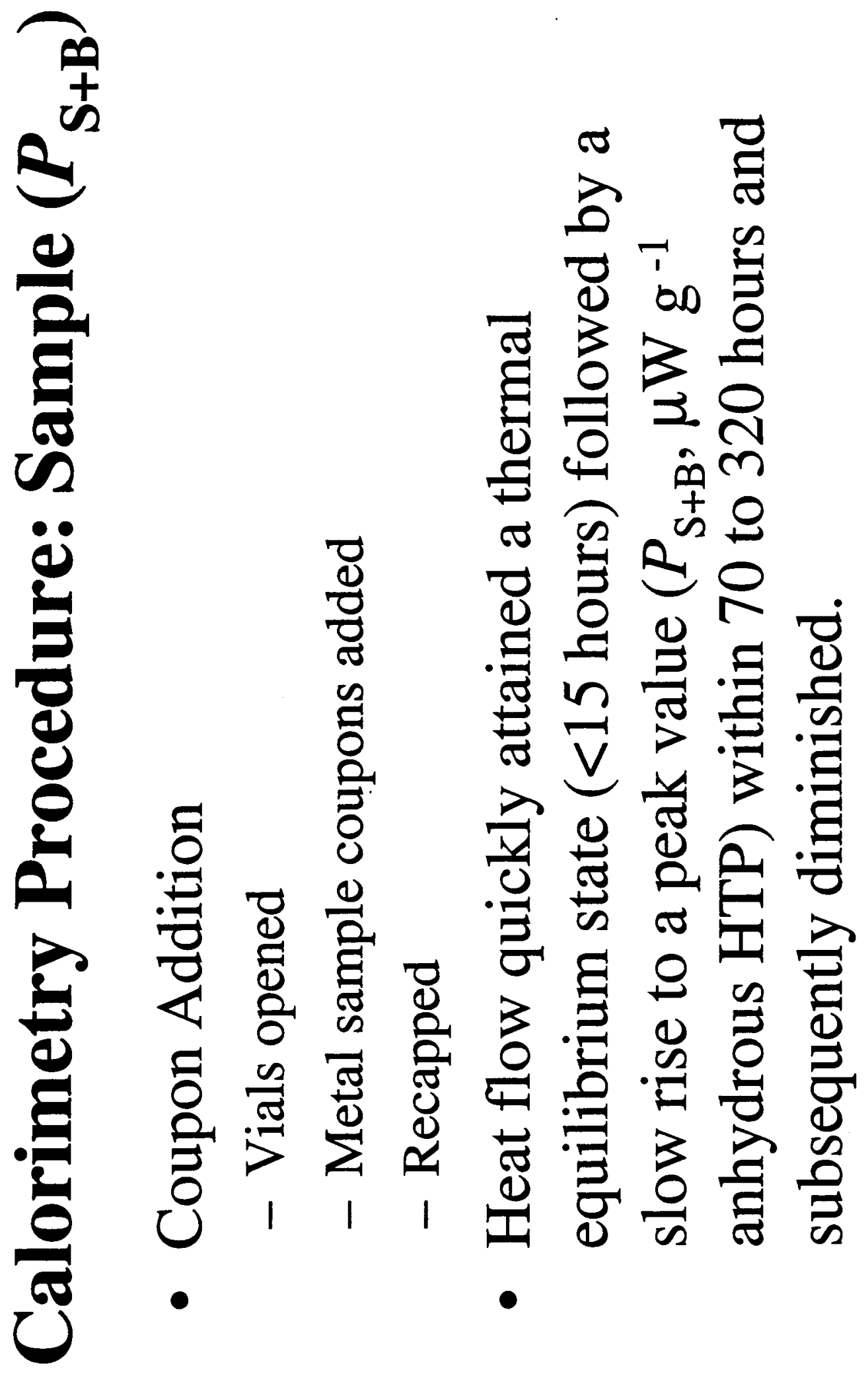




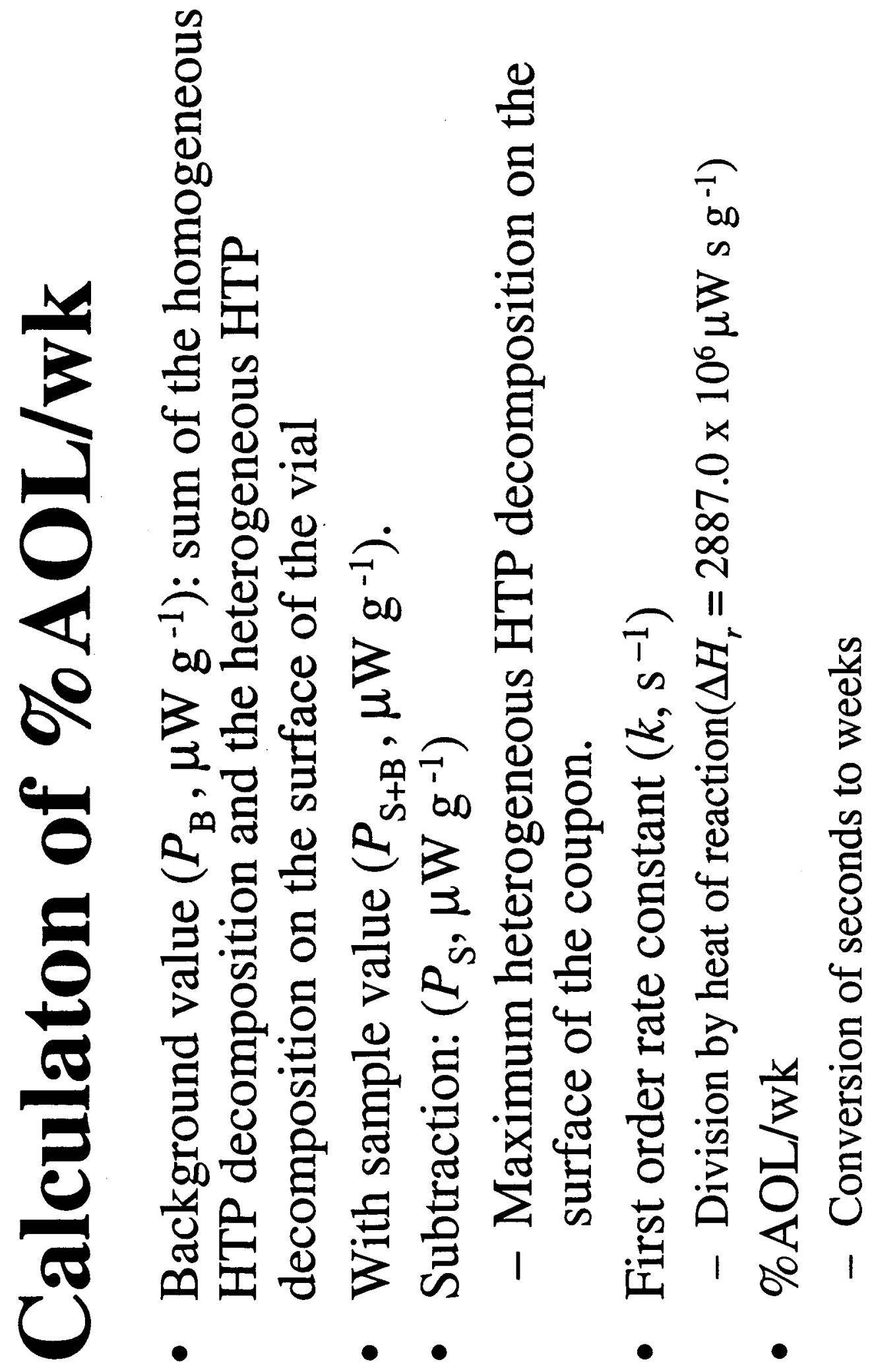




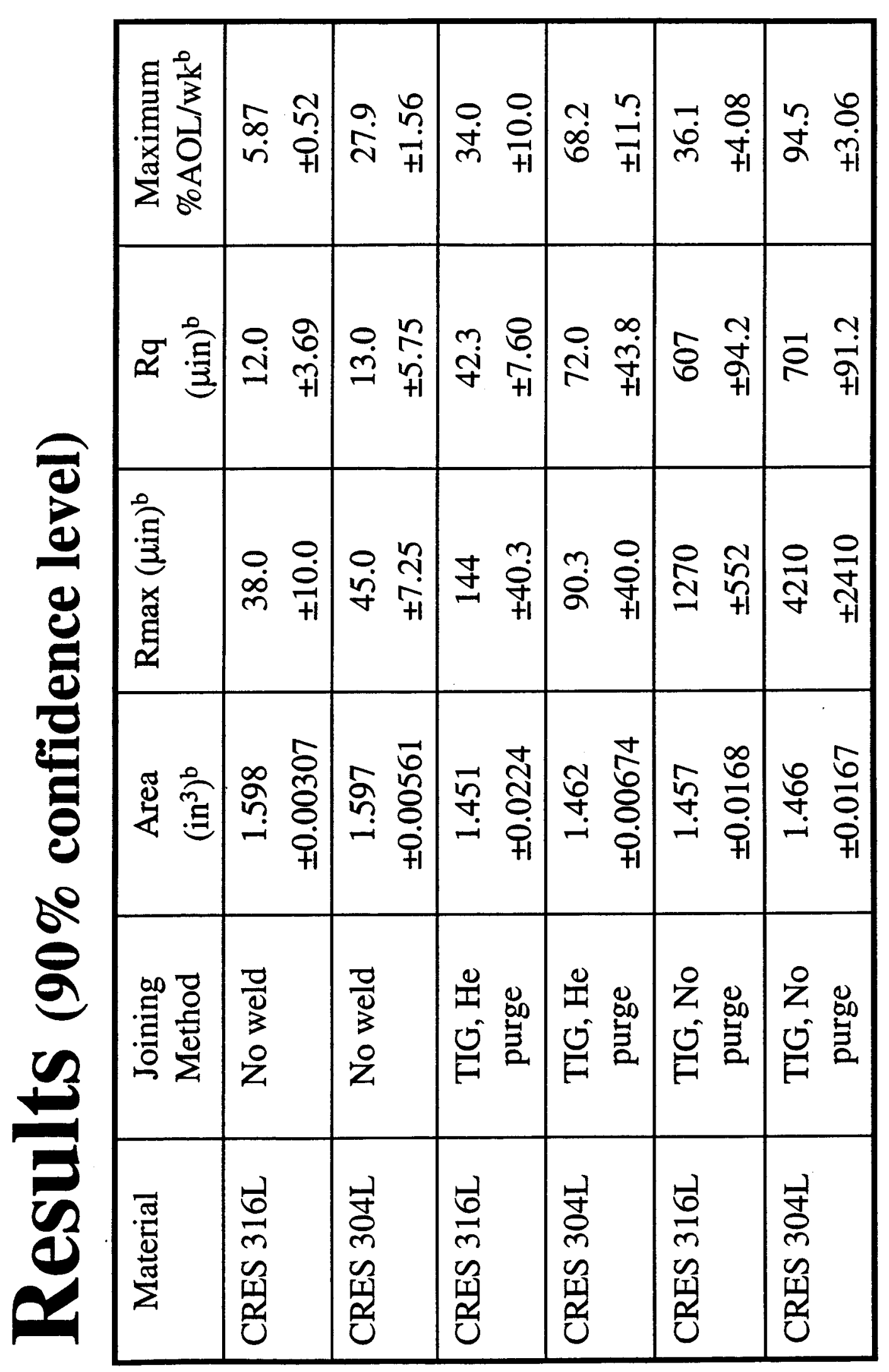




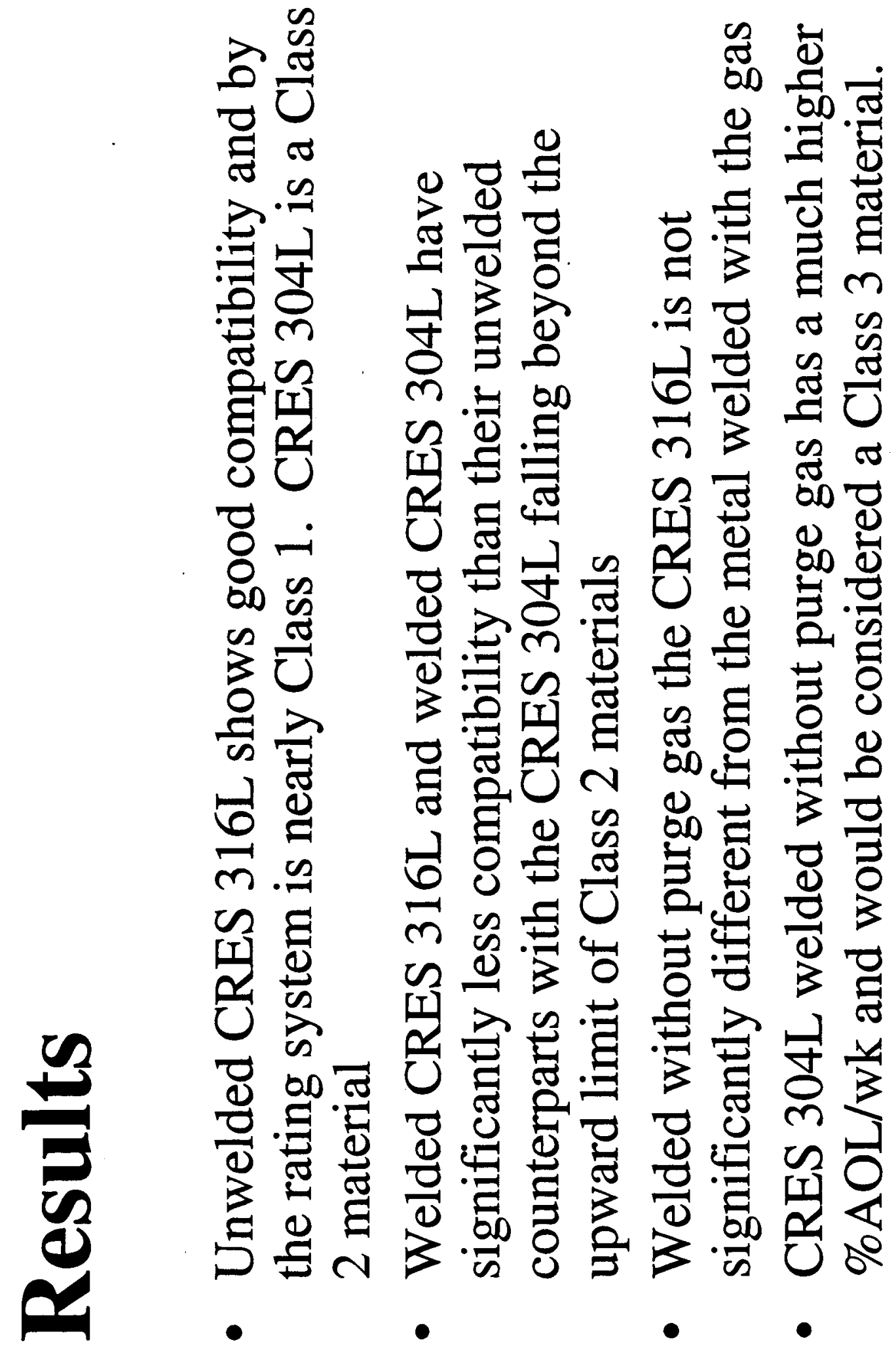




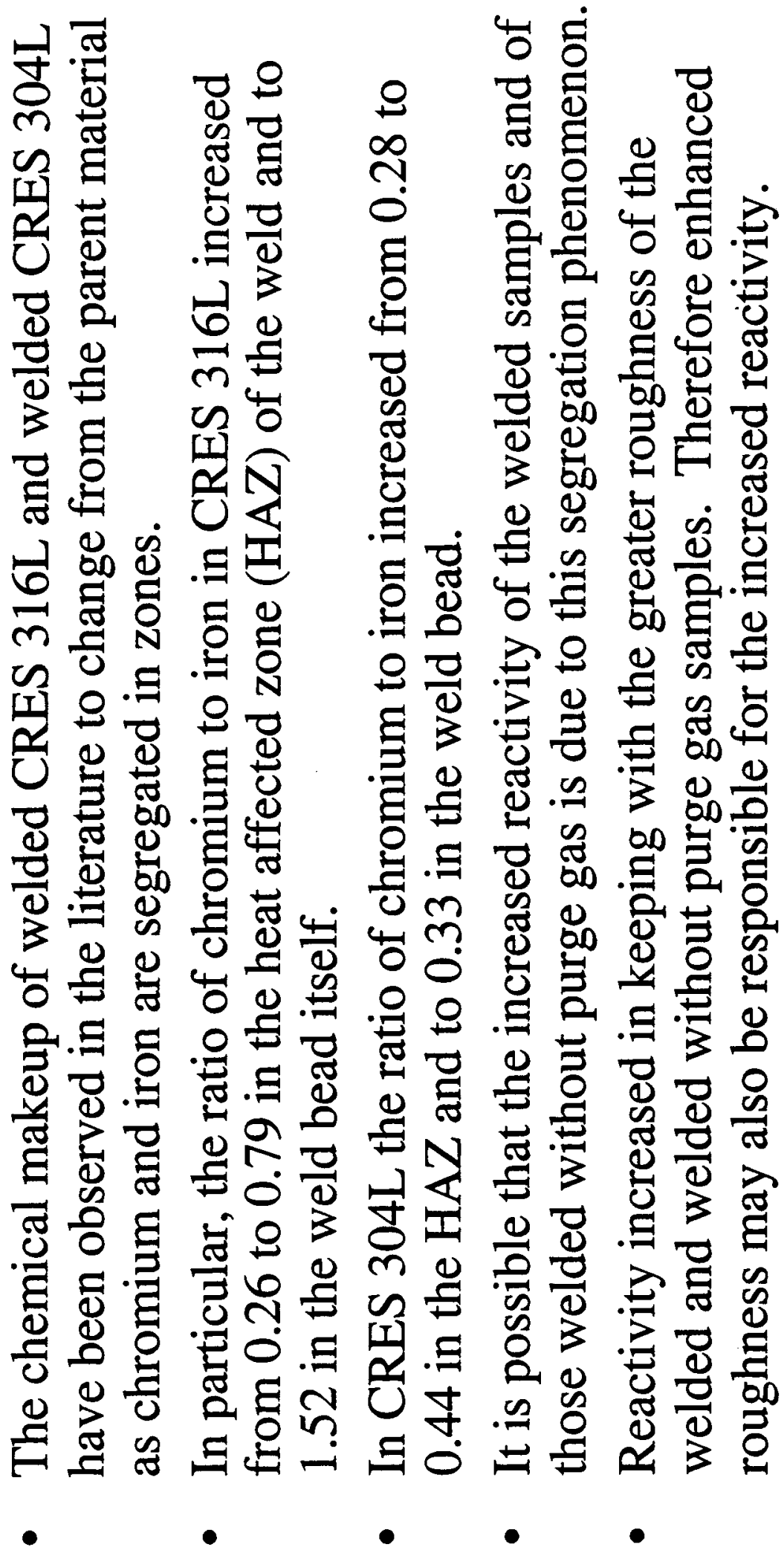




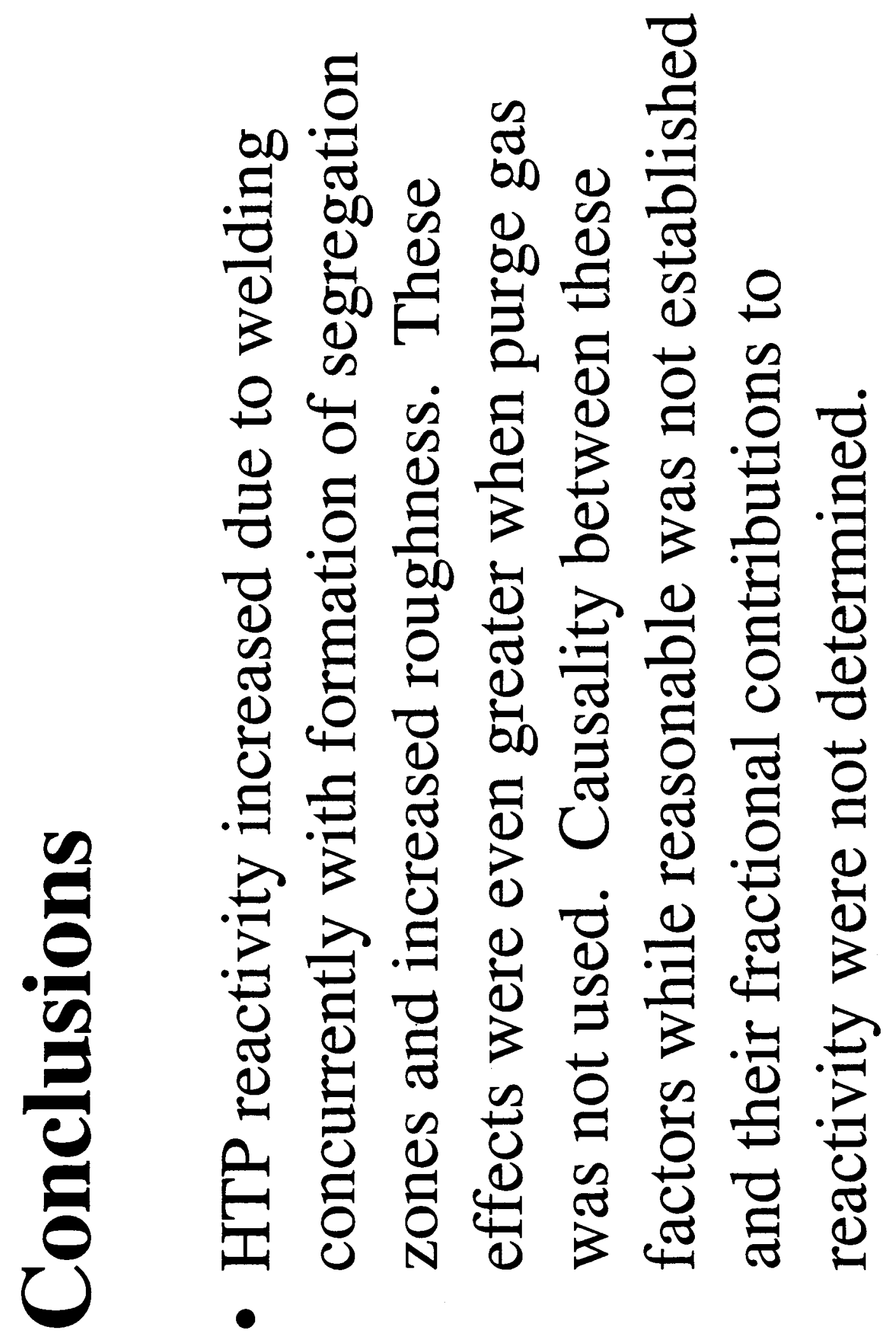




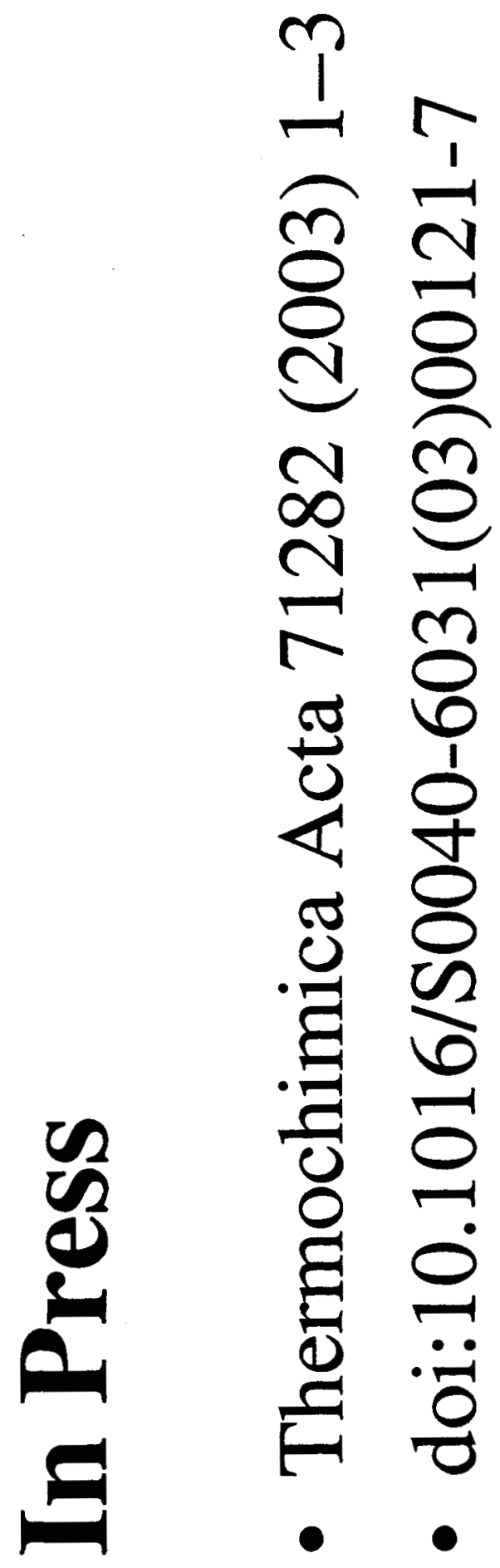




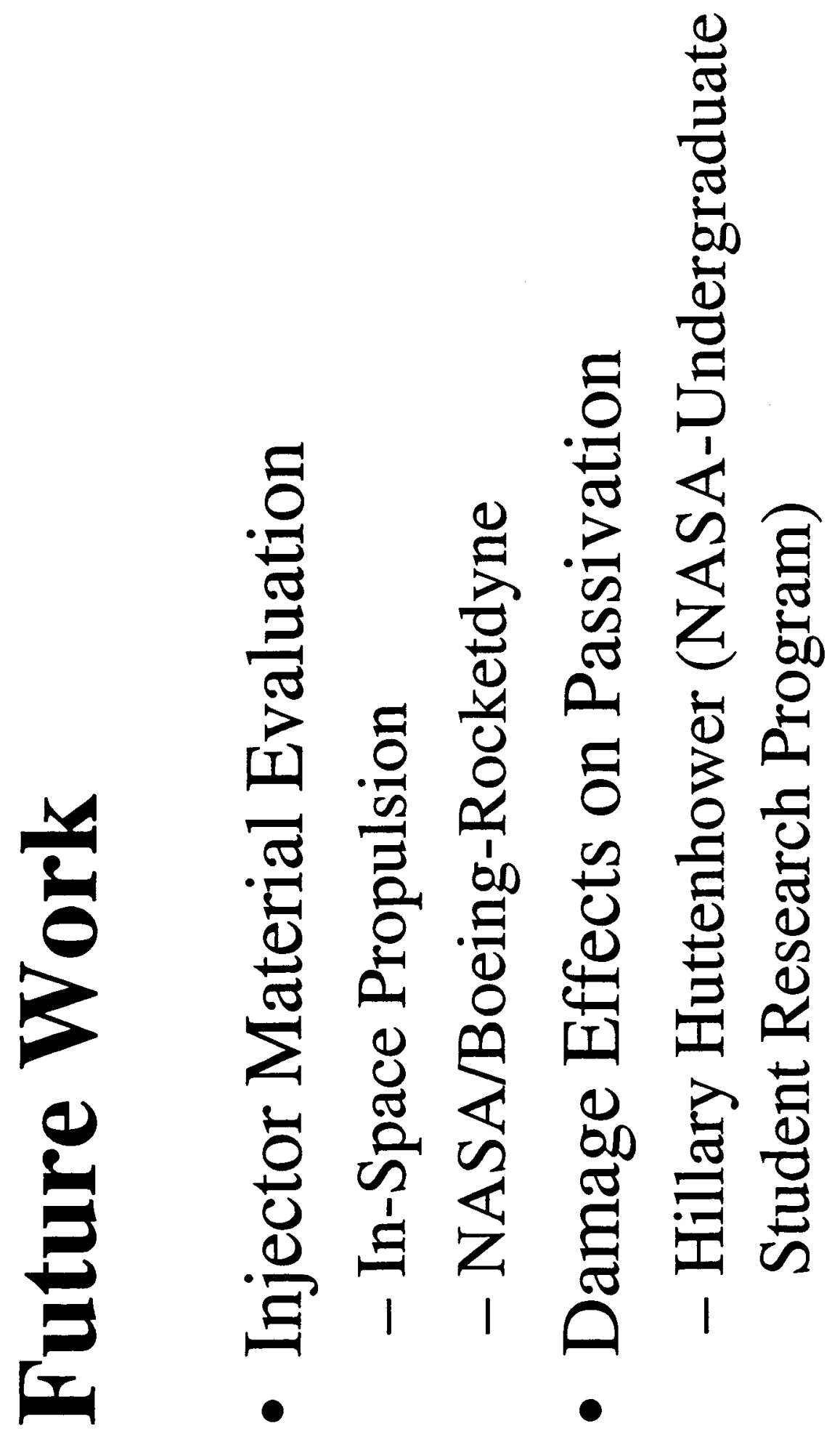




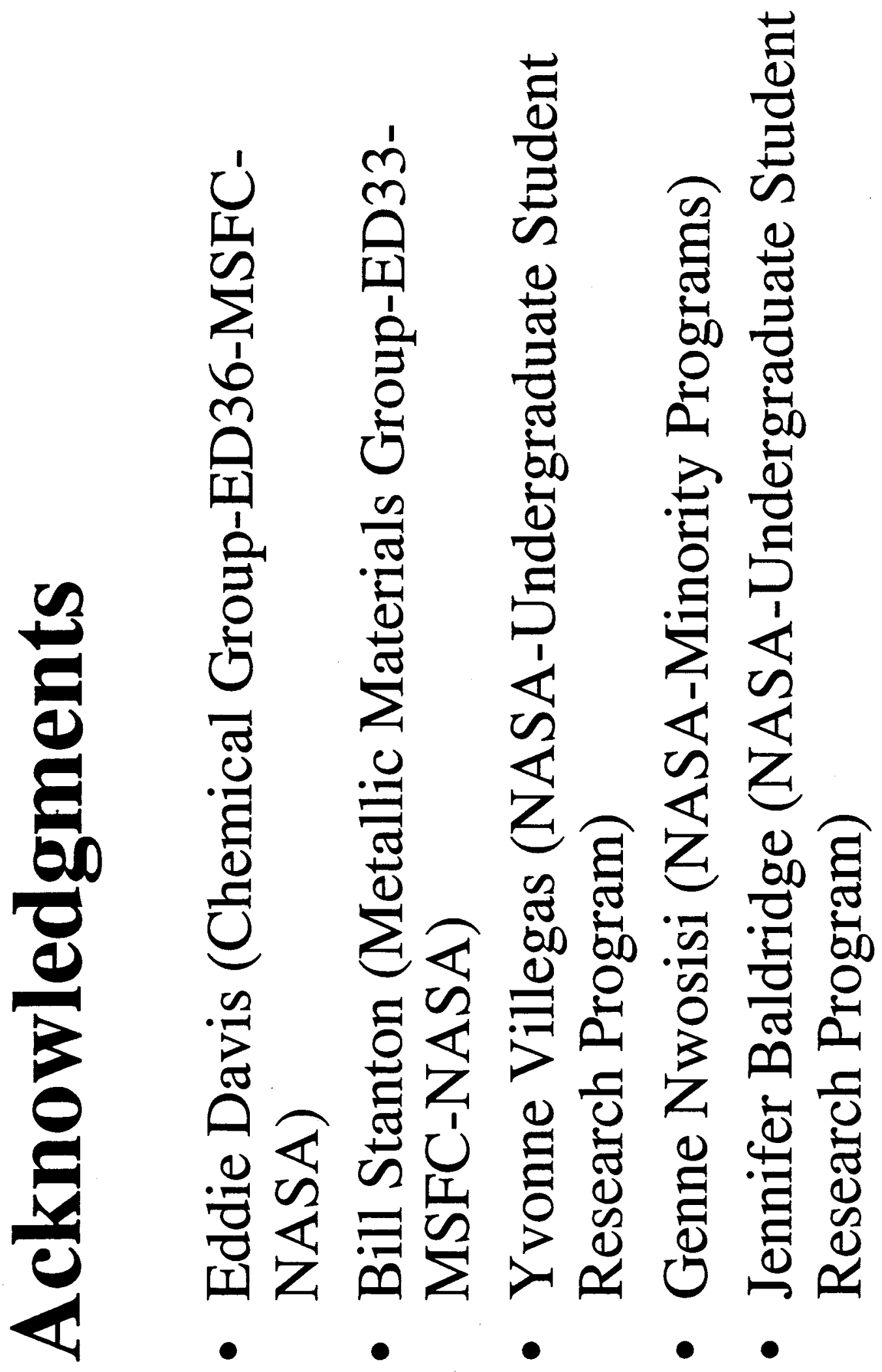




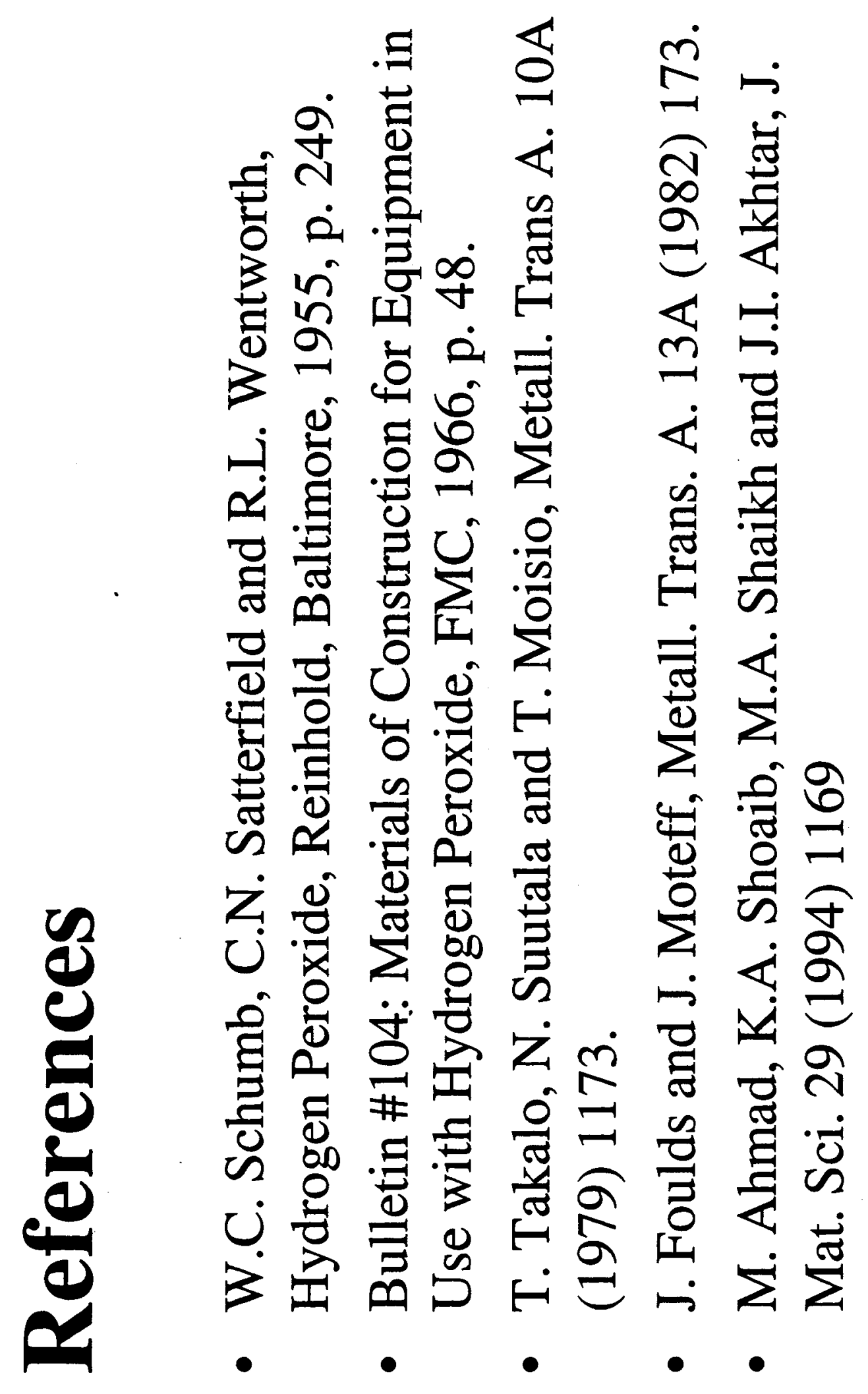

